OPEN ACCESS

Edited by:

Suzie Chen,

Rutgers, The State University of New Jersey, United States

Reviewed by:

Ashley M. Holder,

Houston Methodist Hospital,

United States

Ross Pearlman,

University of Mississippi Medical

Center, United States

*Correspondence:

Weihong Gong

168hongtu@163.com

Specialty section:

This article was submitted to Skin Cancer,

a section of the journal

Frontiers in Oncology

Received: 01 March 2020 Accepted: 04 June 2020

Published: 28 July 2020

Citation:

Zhang F and Gong W (2020)

Prognostic Value of the Platelet-to-Lymphocyte Ratio in

Patients With Melanoma: A Meta-Analysis. Front. Oncol. 10:1116. doi: 10.3389/fonc.2020.01116

\section{Prognostic Value of the Platelet-to-Lymphocyte Ratio in Patients With Melanoma: A Meta-Analysis}

\author{
Feng Zhang ${ }^{1}$ and Weihong Gong ${ }^{2 *}$ \\ ${ }^{1}$ Department of Oncology, Linyi People's Hospital, Linyi, China, ${ }^{2}$ Department of Comprehensive Intervention, Linyi People's \\ Hospital, Linyi, China
}

Background: The prognostic role of the platelet-to-lymphocyte ratio (PLR) is controversial in patients with melanoma. Therefore, we performed a meta-analysis to assess the prognostic value of the PLR in patients with melanoma.

Methods: PubMed, Web of Science, Embase, Cochrane library, WanFang, and China National Knowledge Infrastructure were searched for eligible studies. Pooled hazard ratios (HRs) and 95\% confidence intervals (Cls) were calculated to evaluate the association between the PLR and overall survival (OS) and progression-free survival (PFS).

Results: Nine studies with 2,396 patients were included in this meta-analysis. A high PLR was a predictor of shorter OS (HR $=1.67,95 \% \mathrm{Cl}=1.18-2.38, p=0.004)$, but not PFS ( $\mathrm{HR}=1.53,95 \% \mathrm{Cl}=0.96-2.44, p=0.075)$ in patients with melanoma. Subgroup analysis revealed that the PLR remained a significant prognostic indicator of both OS and PFS in patients with non-metastatic disease; the PLR cutoff value of $<120$ had a consistent prognostic value.

Conclusions: An increased PLR was associated with poor OS of patients with melanoma. Hence, we suggest that the preoperative PLR could be used to identify high-risk patients and provide information regarding the prognosis of patients with melanoma.

Keywords: platelet-to-lymphocyte ratio, meta-analysis, melanoma, prognostic factor, clinical use

\section{INTRODUCTION}

Melanoma is a highly aggressive skin cancer with an increasing incidence rate in Caucasians (1). In $2018, \sim 287,723$ cases of melanoma were newly diagnosed, and 60,712 patients died of melanoma worldwide (2). In the United States, melanoma is the most rapidly increasing malignancy in men and the second most rapidly increasing cancer in women (after lung cancer) (3). Most newly diagnosed patients have localized disease and are curable with surgical excision as the primary treatment (3). For patients with advanced and metastatic stages of the disease, promising treatments include adjuvant and neoadjuvant immunotherapy using immune checkpoint inhibitors, stereotactic radiosurgery, and novel targeted therapies $(4,5)$. The prognosis of patients with stage I disease is excellent, with a 10-year overall survival (OS) rate of $94-98 \%$ (1). However, the prognosis of metastatic melanoma has not sustainably changed over the past 
several decades, with a 10 -year OS rate of only $10-15 \%$ (1). Therefore, identifying simple, low-cost biomarkers is important for developing individualized treatments and evaluating the prognosis of patients.

Recent evidence has demonstrated that cancer-related inflammation plays a crucial role in the development of metastasis in patients with melanoma (6). Several inflammationbased parameters in blood have been explored as prognostic biomarkers for melanoma, including the neutrophil-tolymphocyte ratio (NLR), platelet-to-lymphocyte ratio (PLR), systemic immune-inflammation index, and C-reactive protein (CRP) (7-9). Many studies have confirmed that the PLR is an independent prognostic factor for gastric cancer (10), bladder cancer (11), esophageal cancer (12), breast cancer (13), and non-small-cell lung cancer (14). A number of studies have also explored the prognostic significance of the PLR in patients with melanoma, although the results remain controversial (15-23). For example, some researchers reported that higher pretreatment PLR was a poor prognostic marker for patients with melanoma $(16,17,19)$; whereas some other investigators found that there was a non-significant association between PLR and survival outcomes in melanoma $(18,23)$. Therefore, we performed a meta-analysis to systematically analyze the prognostic value of the PLR in patients with melanoma by using the currently available clinical evidence. We aimed to identify the prognostic significance of PLR in the survival outcomes of patients with melanoma through comparing the prognosis of patients with high and low PLR in prospective trials and retrospective cohort studies.

\section{MATERIALS AND METHODS}

\section{Search Strategy}

The present meta-analysis was conducted according to the Preferred Reporting Items for Systematic Reviews and MetaAnalyses 2009 guidelines (24). We performed a comprehensive literature search of the following databases: PubMed, Web of Science, Embase, Cochrane library, WanFang, and China National Knowledge Infrastructure. The latest search was performed on May 8, 2020. The following search terms were used: "platelet to lymphocyte ratio," "PLR," "platelet-lymphocyte ratio," "platelet lymphocyte ratio," and "melanoma." There were no year or language restrictions. In addition, the references of the papers were also manually checked for potential inclusions. As the study is a meta-analysis and does not involve the collection of samples, ethical approval is not necessary.

\section{Selection Criteria}

The inclusion criteria for eligible studies were as follows: (1) the diagnosis of melanoma was histologically or pathologically confirmed; (2) the PLR values were measured before any treatment; (3) studies provided the data for the association between the PLR and survival outcomes including OS and/or progression-free survival (PFS); (4) the hazard ratio (HR) and $95 \%$ confidence interval (CI) for OS or PFS were reported or enough data were provided to calculate the $\mathrm{HR}$ and $95 \% \mathrm{CI}$; (5) a cutoff value of PLR was identified; and (6) the paper was published in English or Chinese. The exclusion criteria were as follows: (1) duplicate studies; (2) case reports, reviews, comments, and meeting abstracts; (3) non-human studies; and (4) insufficient data to calculate HRs and 95\% CIs.

\section{Data Extraction}

Two investigators (FZ and WG) independently extracted the information from eligible studies via a cross-check, and any disagreements were resolved by discussion. The following information was extracted from each included study: first author's name, year of publication, country of origin, patient age, study period, patient sex, sample size, PLR cutoff value, clinical stage, metastatic status, therapeutic strategy, follow-up, survival outcomes, HRs and 95\% CIs for OS and PFS, and quality scores.

\section{Quality Assessment}

The quality of the included studies was assessed by using the Newcastle-Ottawa Scale (NOS) (25). The NOS comprises three aspects: selection (0-4 stars), comparability (0-2 stars), and outcome (0-3 stars). The NOS score ranges from 0 to 9; studies with a NOS score $\geq 6$ points are regarded as high-quality studies.

\section{Statistical Analysis}

For studies assessing the OS and PFS, the HRs and 95\% CIs were directly extracted if they were reported. Otherwise, the HRs and 95\% CIs were calculated according to the methods described by Tierney et al. (26). The heterogeneity among studies was quantitatively evaluated by using the chi-squared $\mathrm{Q}$ test and the $I^{2}$ metric statistic. If the $p$-value was $<0.10$ on the $\mathrm{Q}$ test or if the $I^{2}>50 \%$, indicative of significant heterogeneity, the randomeffects model was applied. Otherwise, a fixed-effects model was selected. Subgroup analysis was conducted on the basis of sample size, disease status, and the PLR cutoff value. Meta-regression analysis was performed to identify the factors that may cause heterogeneity. Potential publication bias was estimated by using the Begg test (27) and the Egger test (28). All statistical analyses were performed by using Stata software, version 12.0 (Stata Corp., College Station, TX, USA). $P<0.05$ were considered statistically significant.

\section{RESULTS}

\section{Search Results and the Description of the Studies}

The initial literature search yielded 85 records, and 53 studies were further scanned after the removal of duplicates. Then, 40 studies were excluded after screening the title and abstract, following which, 13 studies were evaluated by examining the full text. Subsequently, four studies were eliminated owing to the following reasons: two articles had insufficient data, one was a duplicate study with overlapping patients, and one did not focus on melanoma. Finally, nine studies (15-23) were included in this meta-analysis. Figure 1 illustrates the searching and selection process of the included studies. The included studies were published between 2016 and 2019. The included studies encompassed a total of 2,396 patients, ranging from 21 to 1,351 patients, with a median value of 140 . The studies were conducted in four countries, including China $(n=6)(16,17,19,21-23)$, Canada $(n=1)(15)$, Japan $(n=1)(18)$, and the UK $(n=$ 


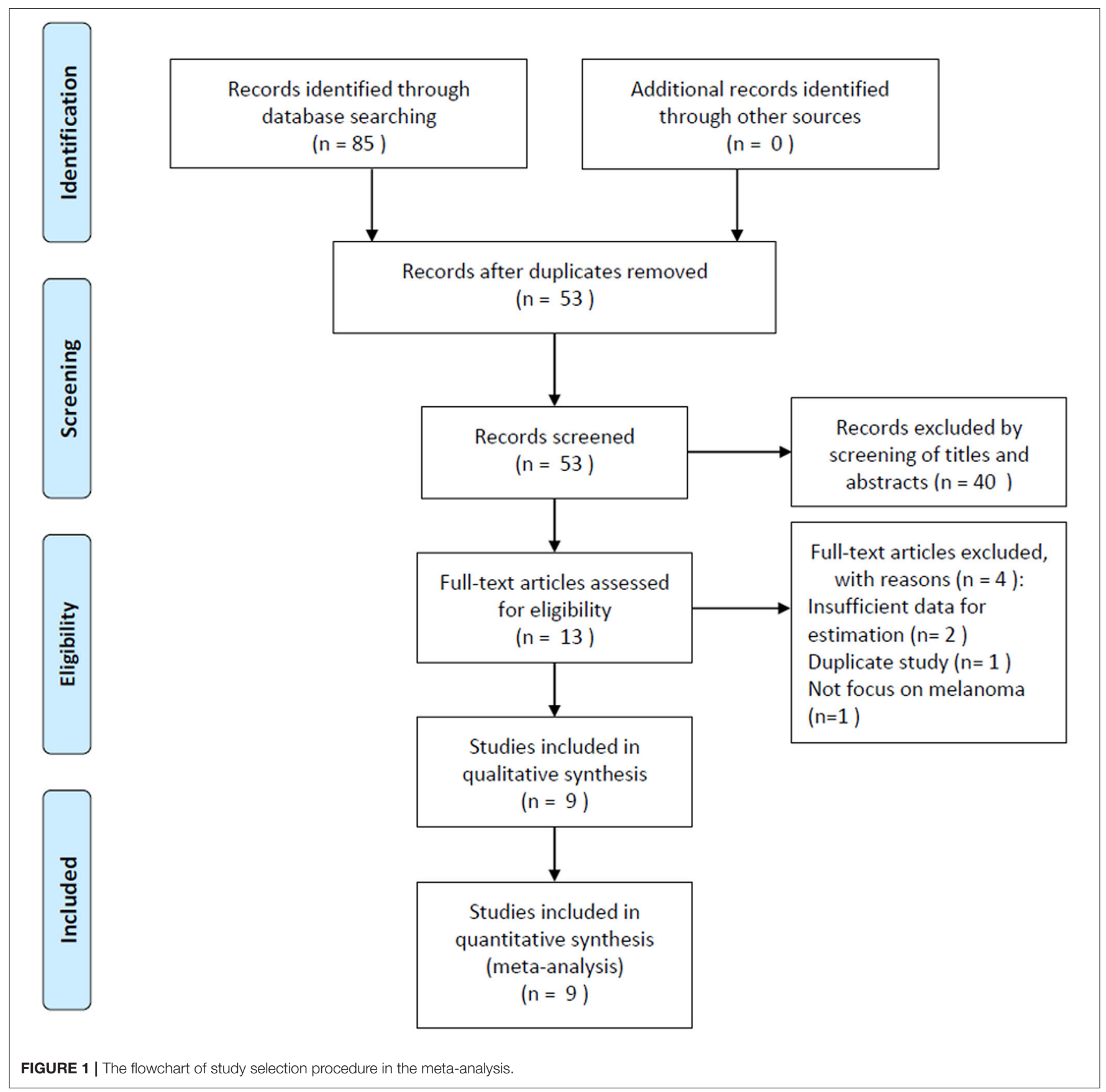

1) (20). Seven studies were published in English (15, 16, 18$20,22,23)$, and two were in Chinese $(17,21)$. Eight studies with 2,341 patients (15-22) provided the data for OS, and five studies with 1,892 patients $(15,16,20,22,23)$ presented the prognostic value of the PLR considering PFS. The cutoff values of the PLR ranged from 99 to 206; the median value was 120. Patients who underwent surgery were included in three studies $(17,20$, $21)$, patients who received mixed treatment were included in two studies $(19,22)$, and patients receiving anti-cytotoxic $\mathrm{T}$ lymphocyte-associated protein (CTLA)-4 (15), interferon (IFN)$\alpha$-2b (16), anti-PD-1 (18), or chemotherapy (23) were included in one study each. The main characteristics of the included studies are shown in Table 1. The NOS scores for all the studies ranged from 6 to 9, indicating that all the included studies were of high quality.

\section{The Association Between the Platelet-to-Lymphocyte Ratio and Overall Survival in Patients With Melanoma}

The association between the PLR and OS was reported in eight studies including 2,341 patients (15-22). The HRs and 95\% CIs 
TABLE 1 | Characteristics of the included studies in this meta-analysis.

\begin{tabular}{|c|c|c|c|c|c|c|c|c|c|c|c|c|c|}
\hline Author & Year & Country & $\begin{array}{l}\text { Sample } \\
\text { size }\end{array}$ & $\begin{array}{c}\text { Age } \\
\text { median } \\
\text { (range) }\end{array}$ & $\begin{array}{c}\text { Sex } \\
\text { (male/female) }\end{array}$ & $\begin{array}{l}\text { Disease } \\
\text { status }\end{array}$ & $\begin{array}{l}\text { Study } \\
\text { period }\end{array}$ & Stage & Treatment & $\begin{array}{c}\text { Follow-up } \\
\text { (months) } \\
\text { Median (range) }\end{array}$ & $\begin{array}{l}\text { Cutoff } \\
\text { value }\end{array}$ & $\begin{array}{l}\text { NOS } \\
\text { score }\end{array}$ & $\begin{array}{l}\text { Survival } \\
\text { analysis }\end{array}$ \\
\hline Khoja & 2016 & Canada & 183 & 58 (24-89) & $115 / 68$ & Metastatic & 2008-2015 & IV & Anti-CTLA-4 & $7.5(0.3-49.5)$ & 182 & 8 & OS, PFS \\
\hline Yu & 2017 & China & 263 & NR & NR & Metastatic & 2010-2016 & IV & $\mathrm{IFN}-\alpha-2 \mathrm{~b}$ & To October 2016 & 129 & 6 & OS, PFS \\
\hline Cao & 2018 & China & 120 & 57 (19-86) & $67 / 53$ & $\begin{array}{l}\text { Non } \\
\text { metastatic }\end{array}$ & 2007-2012 & $|-|||$ & Surgery & 93 & 99 & 7 & OS \\
\hline Minowa & 2018 & Japan & 21 & 74 (34-91) & $11 / 10$ & Metastatic & 2014-2017 & IV & Anti-PD-1 & NR & 159 & 6 & OS \\
\hline Qi & 2018 & China & 140 & $56.4(22-81)$ & $69 / 71$ & Mixed & 2010-2015 & I-IV & Mixed & $21.5(1-80)$ & 120 & 8 & OS \\
\hline Wade & 2018 & UK & 1351 & NR & $678 / 673$ & $\begin{array}{l}\text { Non } \\
\text { metastatic }\end{array}$ & 2006-2016 & $|-|||$ & Surgery & $45.6(3-128.4)$ & 100 & 9 & OS, PFS \\
\hline Wang & 2019 & China & 223 & $55.6(18-85)$ & $136 / 87$ & $\begin{array}{l}\text { Non } \\
\text { metastatic }\end{array}$ & 2005-2015 & $|-|||$ & Surgery & To May 2018 & 113.6 & 7 & OS \\
\hline Wang & 2019 & China & 40 & 58 & $14 / 26$ & Mixed & 2010-2017 & I-IV & Mixed & 47.8 (7.8-88.9) & 118.7 & 8 & OS, PFS \\
\hline Yang & 2019 & China & 55 & $58(38-75)$ & 23/32 & Metastatic & 2013-2018 & III-IV & Chemotherapy & y $19.2(2.9-37.1)$ & 206 & 7 & PFS \\
\hline
\end{tabular}

OS, overall survival; PFS, progression-free survival; NR, not reported; IFN- $\alpha-2 b$, interferon alfa-2b; NOS, Newcastle-Ottawa Scale.

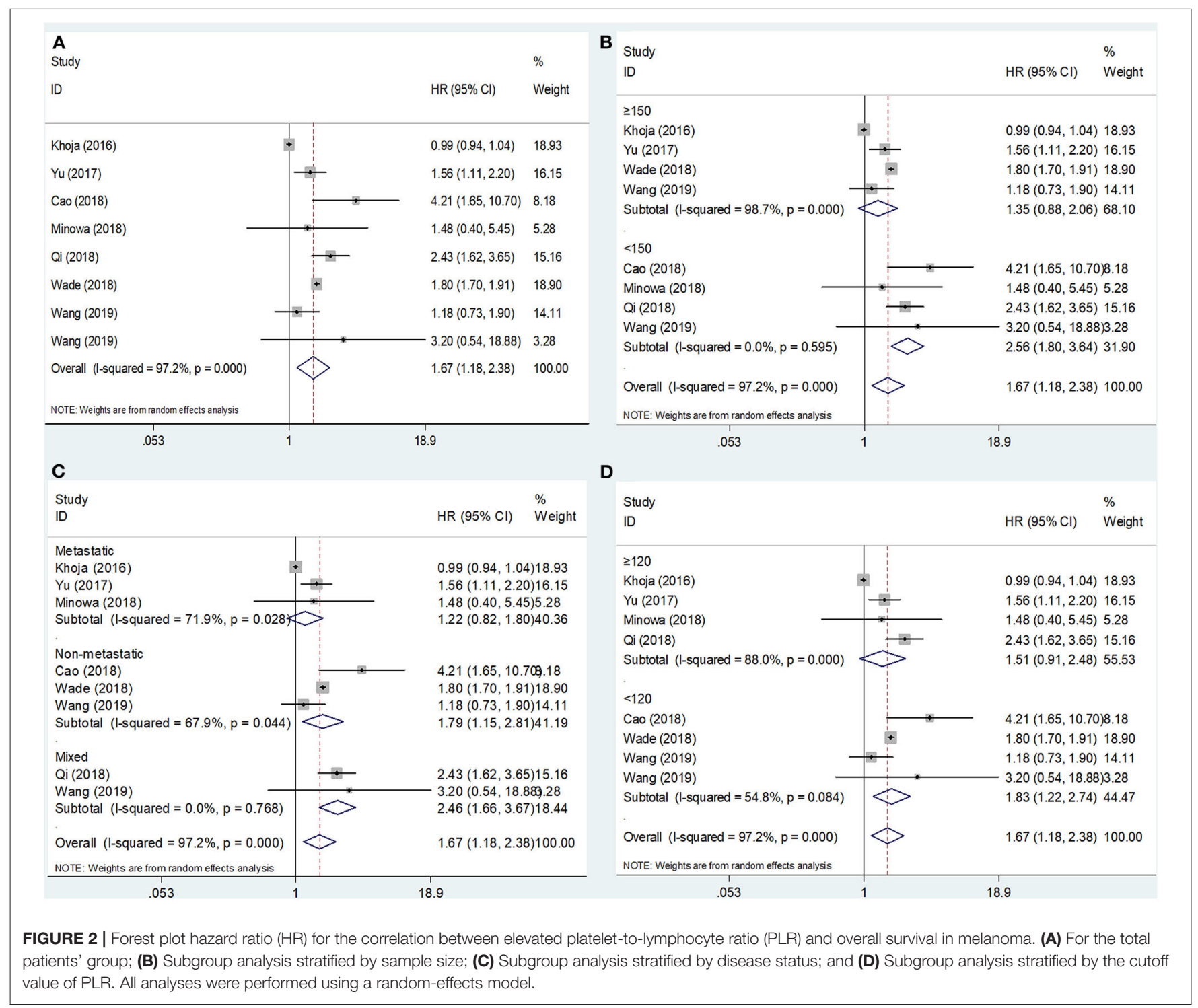


TABLE 2 | The subgroup analysis between PLR and the prognosis of patients with melanoma.

\begin{tabular}{|c|c|c|c|c|c|c|c|c|}
\hline Variables & No. of studies & No. of patients & Effects model & HR (95\% Cl) & $p$ & \multicolumn{2}{|c|}{$\begin{array}{l}\text { Heterogeneity } \\
\qquad I^{2}(\%) P\end{array}$} & $\begin{array}{c}\text { Meta-regression } \\
\boldsymbol{p}\end{array}$ \\
\hline Sample size & & & & & & & & 0.066 \\
\hline$<150$ & 4 & 321 & Fixed & $2.56(1.80-3.64)$ & $<0.001$ & 0 & 0.595 & \\
\hline$\geq 150$ & 4 & 2020 & Random & $1.35(0.88-2.06)$ & 0.166 & 98.7 & $<0.001$ & \\
\hline Non-metastatic & 3 & 1694 & Random & $1.79(1.15-2.81)$ & 0.011 & 67.9 & 0.044 & \\
\hline Metastatic & 3 & 467 & Random & $1.22(0.82-1.80)$ & 0.325 & 71.9 & 0.028 & \\
\hline Mixed & 2 & 180 & Fixed & $2.46(1.66-3.67)$ & $<0.001$ & 0 & 0.768 & \\
\hline PLR cutoff value & & & & & & & & 0.516 \\
\hline$<120$ & 4 & 607 & Random & $1.83(1.22-2.74)$ & 0.003 & 54.8 & 0.084 & \\
\hline$\geq 120$ & 4 & 1734 & Random & $1.51(0.91-2.48)$ & 0.108 & 88.0 & $<0.001$ & \\
\hline$<150$ & 2 & 95 & Fixed & $1.92(1.01-3.63)$ & 0.045 & 0 & 0.979 & \\
\hline$\geq 150$ & 3 & 1797 & Random & $1.41(0.82-2.45)$ & 0.216 & 97.7 & $<0.001$ & \\
\hline Disease status & & & & & & & & 0.274 \\
\hline Non-metastatic & 1 & 1351 & - & $1.90(1.67-2.16)$ & $<0.001$ & - & - & \\
\hline Metastatic & 3 & 501 & Random & $1.27(0.82-1.96)$ & 0.288 & 54.2 & 0.112 & \\
\hline Mixed & 1 & 40 & - & $1.95(0.48-8.02)$ & 0.353 & - & - & \\
\hline PLR cut-off value & & & & & & & & 0.266 \\
\hline$<120$ & 2 & 1391 & Fixed & $1.90(1.67-2.16)$ & $<0.001$ & 0 & 0.970 & \\
\hline$\geq 120$ & 3 & 501 & Random & $1.27(0.82-1.96)$ & 0.288 & 54.2 & 0.112 & \\
\hline
\end{tabular}

OS, overall survival; PFS, progression-free survival; PLR, plate-to-lymphocyte ratio.

were extracted and combined by using a random-effects model because of significant heterogeneity $\left(I^{2}=97.2 \%, p<0.001\right.$; Figure 2A; Table 2). The pooled HR and 95\% CI were 1.67 and $1.18-2.38$, respectively $(p=0.004)$, suggesting that a high PLR was correlated with poor OS. Then, subgroup analysis was conducted to determine the source of heterogeneity. Regarding the sample size, an elevated PLR was associated with poor OS of studies enrolling cases $<150(\mathrm{HR}=2.56,95 \% \mathrm{CI}=1.80-3.64, p$ $<0.001)$ but not of studies with a sample size $\geq 150$ ( $\mathrm{HR}=1.35$, $95 \% \mathrm{CI}=0.88-2.06, p=0.166$; Figure 2B; Table 2). Considering the disease status, a high PLR predicted poor OS in patients with non-metastatic disease $(\mathrm{HR}=1.79,95 \% \mathrm{CI}=1.15-2.81, p=$ $0.011)$ and those with mixed status $(\mathrm{HR}=2.46,95 \% \mathrm{CI}=1.66-$ 3.67, $p<0.001$ ), but not in those with metastatic disease (HR $=1.22,95 \% \mathrm{CI}=0.82-1.80, p=0.325$; Figure 2C; Table 2). Regarding the cutoff value of the PLR, a PLR of $<120$ remained a significant prognostic factor for OS ( $\mathrm{HR}=1.83,95 \% \mathrm{CI}=1.22-$ $2.74, p=0.003$ ), whereas a PLR of $\geq 120$ was not significant (HR $=1.51,95 \% \mathrm{CI}=0.91-2.48, p=0.108$; Figure 2D; Table 2).

\section{The Association Between the}

\section{Platelet-to-Lymphocyte Ratio and Progression-Free Survival in Patients With Melanoma}

The PFS outcomes from five studies comprising 1,892 patients were analyzed $(15,16,20,22,23)$. The heterogeneity was significant $\left(I^{2}=95.5 \%, p<0.001\right)$; therefore, a random-effects model was applied. The pooled results suggested that an elevated PLR was not significantly correlated with PFS (HR $=1.53$, 95\% $\mathrm{CI}=0.96-2.44, p=0.075$; Figure 3A; Table 2). On subgroup analysis, the pooled data showed that a high PLR was correlated with poor PFS in studies with a sample size $<150(\mathrm{HR}=1.92$, $95 \% \mathrm{CI}=1.01-3.63, p=0.045$; Figure 3B; Table 2) and in those with non-metastatic disease $(\mathrm{HR}=1.90,95 \% \mathrm{CI}=1.67-2.16, p$ $<0.001$; Figure 3C; Table 2), as well as when the cutoff value of the PLR was $<120$ (HR $=1.90,95 \% \mathrm{CI}=1.67-2.16, p<0.001$; Figure 3D; Table 2). However, the PLR was not associated with the PFS in studies with a sample size $\geq 150$ and in those with metastatic and mixed disease, as well as when the cutoff value of the PLR was $\geq 120$ (Table 2 ).

\section{Meta-Regression Analysis}

We performed a meta-regression analysis to determine the factor (sample size, disease status, or cutoff value) that may cause heterogeneity. As shown in Table 2, the data suggested that sample size, disease status, and the cutoff value did not result in significant heterogeneity in OS and PFS ( $p>0.05$ for all).

\section{Publication Bias}

For the meta-analysis with OS and PFS, the publication bias was assessed by using the Begg test and the Egger test. For OS, the $p$-value on the Begg test was 0.902 (Figure 4A), and the $p$-value on the Egger test was 0.575 (Figure 4B). For PFS, the $p$-value on 


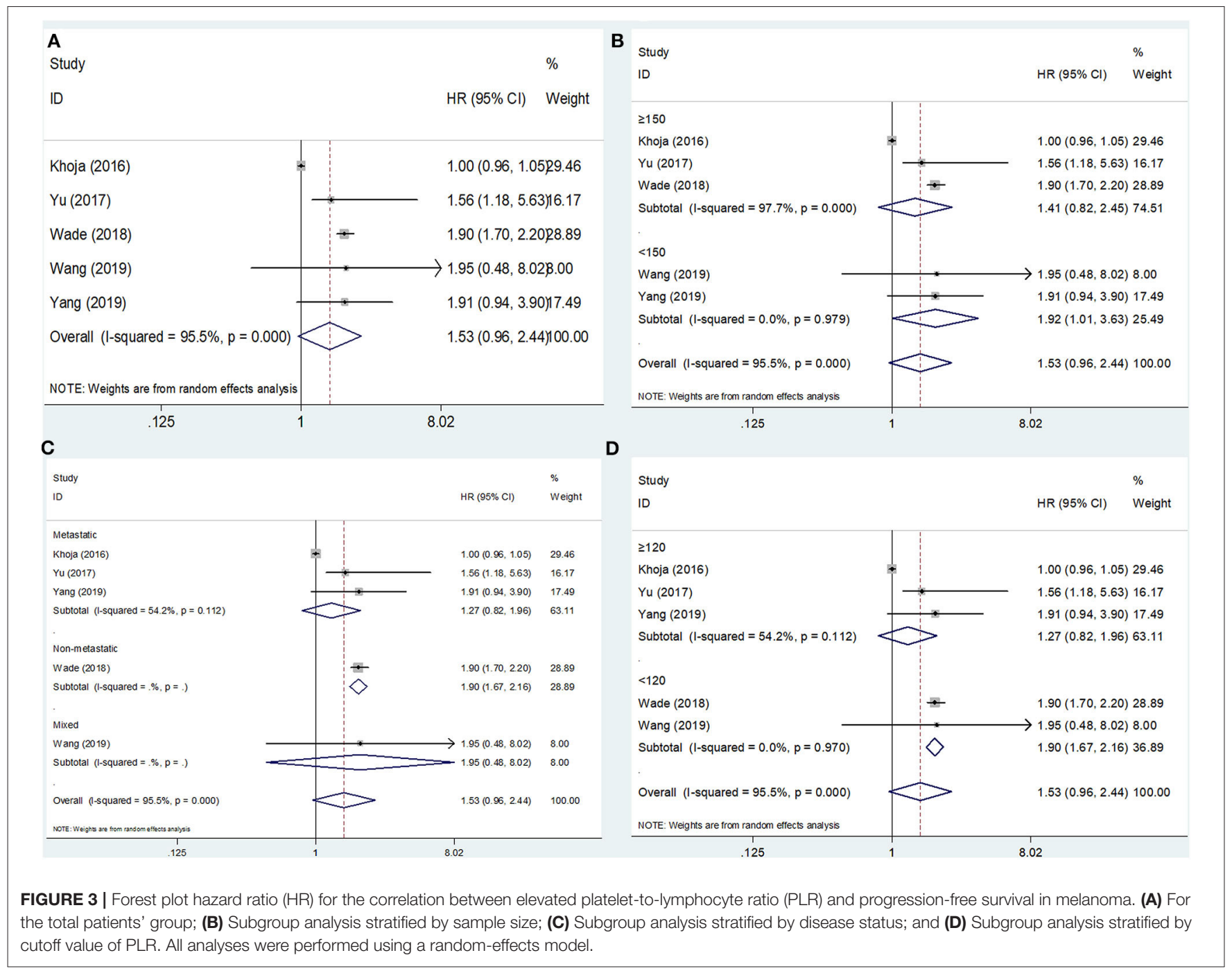

the Begg test was 0.806 (Figure 4C), and the $p$-value on the Egger test was 0.350 (Figure 4D). The results revealed that there was no significant publication bias in the current meta-analysis.

\section{DISCUSSION}

Inflammation responses play an important role in tumor initiation, progression, and metastasis (29). Many inflammatory indicators-derived from the peripheral blood-and cancerrelated inflammatory cells have been investigated as prognostic factors for melanoma, such as the NLR, PLR, CRP, and tumor-infiltrating lymphocytes (TILs) $(7,30,31)$. Although the prognostic utility of the PLR has been evaluated in patients with melanoma, the results are still controversial (15-17, 19, 20, 22). Therefore, in the current meta-analysis, we pooled the data from nine studies and found that an elevated PLR was associated with poor OS but not PFS of patients with melanoma. The results of subgroup analysis indicated that an elevated PLR predicted poor OS in most subpopulations. In addition, the PLR remained a significant prognostic indicator for patients with non-metastatic disease; moreover, the PLR cutoff value of $<120$ had a consistent prognostic value. Those findings suggested that the PLR was more sensitive regarding the prognosis of patients with localized tumors. Furthermore, a PLR $<120$ showed a more potent prognostic efficacy for the prognostication of melanoma. Taken together, the results of our study demonstrated that a high PLR was associated with poor OS of patients with melanoma. Moreover, our results suggested that the PLR could serve as a promising prognostic parameter for melanoma. To the best of our knowledge, the current study is the first meta-analysis to identify the association between the PLR and survival outcomes of patients with melanoma.

Cancer-related systemic inflammation plays an essential role in every step of tumor development, including proliferation, angiogenesis, and metastasis (32). A high PLR is the result of an increase in platelets and/or a low lymphocyte count. Platelets are critical sources of cytokines and can facilitate tumor progression by sustaining proliferative signaling (33), support tumor growth and metastasis (34), and protect cancer cells from apoptosis 

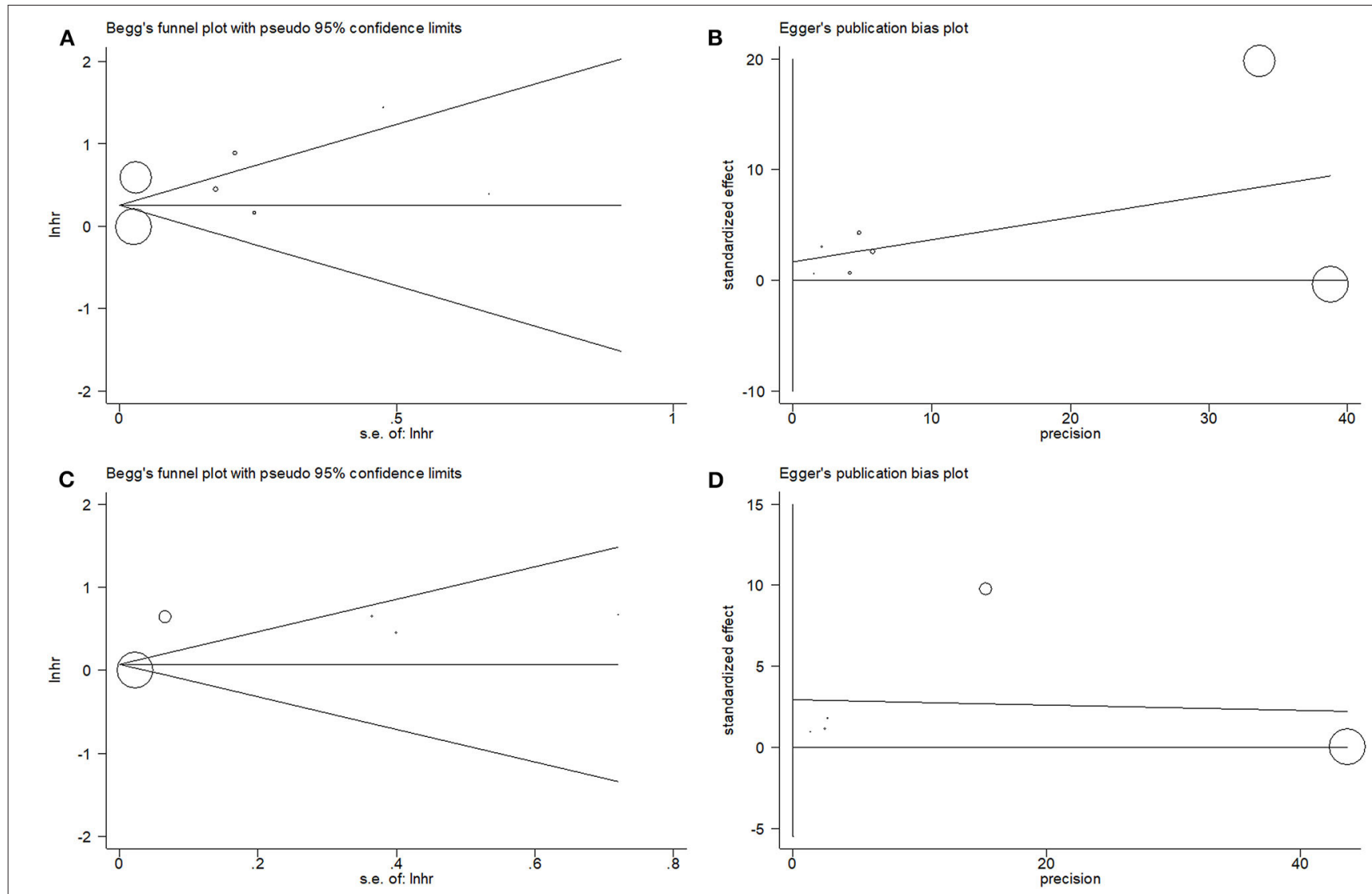

FIGURE 4 | Begg's funnel plot and Egger's test to evaluate publication bias. (A) Begg's test for overall survival (OS); (B) Egger's test for OS; (C) Begg's test for progression-free survival (PFS); and (D) Egger's test for PFS.

(35) through their secretion of interleukin (IL)-6, tumor necrosis factor (TNF)- $\alpha$, and platelet-derived growth factor (PDGF), among other factors. In addition, platelets can support tumor cells in evading the immune system of the host (36). In contrast, lymphocytes, especially TILs, play a vital role in T cell-mediated antitumor response (37). Lymphocytes exert an antitumor effect via the induction of cytotoxic cell death as well as the suppression of tumor proliferation through the secretion of IL-4, IL-5, and TNF- $\beta$ (38). Many studies showed that a low lymphocyte count was correlated with poor prognoses of multiple malignancies (39-41). Therefore, a high PLR could be an indicator of the low antitumor capacity and thus predict poor prognosis.

Many studies have investigated the prognostic significance of the PLR in human tumors through meta-analyses $(42,43)$. A recent meta-analysis including 28 studies with 15,617 patients indicated that an elevated PLR was associated with poor OS of patients with gastric cancer (44). Another meta-analysis also revealed that the pretreatment PLR was a simple, promising prognostic indicator of OS and PFS of patients with ovarian and cervical cancers (45). Furthermore, a high PLR was associated with poor prognosis in patients with nasopharyngeal carcinoma (46). In the current meta-analysis, we identified the PLR as a prognostic factor for OS but not for PFS in patients with melanoma; the non-significant prognostic value for PFS may be the result of the limited studies included. The observations of the current study are in accordance with the findings for bladder cancer (47) and diffuse large B-cell lymphoma (48). Nevertheless, the prognostic value of PLR for PFS needs to be further explored in large-scale prospective trials.

This study has several limitations. First, the sample size was relatively small; only nine studies with 2,396 patients were included in this meta-analysis. For PFS analysis, only five studies were eligible, and the association between the PLR and clinicopathological features of melanoma could not be analyzed because of insufficient data. As the sample size was limited, the persuasiveness of the results may be compromised. Second, the cutoff value of the PLR was different among the included studies. A standard value for a high PLR is needed to facilitate the wide application of the PLR in clinical practice. Third, the obvious heterogeneity of the included studies cannot be ignored. Although we adopted the random-effects model to analyze data when the heterogeneity was significant, the heterogeneity still existed. We also conducted a meta-regression analysis, wherein the results suggested that sample size, disease status, and the cutoff value did not result in significant heterogeneity. Accordingly, the source of the heterogeneity could be the retrospective nature of the included studies, selection bias of patients, and diverse treatment methods. Therefore, we suggest 
that well-designed, prospective trails be conducted in the future to verify the results of the current meta-analysis.

In summary, the results of the present meta-analysis demonstrated that an elevated PLR was associated with poor OS of patients with melanoma. Moreover, the PLR remained a significant prognostic indicator for patients with non-metastatic disease; in addition, the PLR cutoff value of $<120$ had a consistent prognostic value. We recommend that the pretreatment PLR be used to identify high-risk patients and determine the prognosis of patients with melanoma.

\section{REFERENCES}

1. O’Neill CH, Scoggins CR. Melanoma. J Surg Oncol. (2019) 120:873-81. doi: $10.1002 /$ jso. 25604

2. Bray F, Ferlay J, Soerjomataram I, Siegel RL, Torre LA, Jemal A. Global cancer statistics 2018: GLOBOCAN estimates of incidence and mortality worldwide for 36 cancers in 185 countries. CA Cancer J Clin. (2018) 68:394-424. doi: $10.3322 /$ caac. 21492

3. Coit DG, Thompson JA, Albertini MR, Barker C, Carson WE, Contreras C, et al. Cutaneous melanoma version 2.2019. J Natl Compr Canc Netw. (2019) 17:367-402. doi: 10.6004/jnccn.2019.0018

4. Richtig E. ASCO Congress 2018: melanoma treatment. Memo. (2018) 11:2615. doi: 10.1007/s12254-018-0455-4

5. Occelli M, Vandone AM, Cauchi C, Merlano MC. Melanoma: the new perspectives from clinical and translational research. Anti Cancer Drugs. (2019) 30:543-53. doi: 10.1097/CAD.0000000000000798

6. Antohe M, Nedelcu RI, Nichita L, Popp CG, Cioplea M, Brinzea A, et al. Tumor infiltrating lymphocytes: the regulator of melanoma evolution. Oncol Lett. (2019) 17:4155-61. doi: 10.3892/ol.2019.9940

7. Ding Y, Zhang S, Qiao J. Prognostic value of neutrophil-to-lymphocyte ratio in melanoma: evidence from a PRISMA-compliant meta-analysis. Medicine. (2018) 97:e11446. doi: 10.1097/MD.0000000000011446

8. Yang RN, Chang Q, Meng XC, Gao N, Wang WH. Prognostic value of Systemic immune-inflammation index in cancer: a meta-analysis. J Cancer. (2018) 9:3295-302. doi: 10.7150/jca.25691

9. Robinson AV, Keeble C, Lo MCI, Thornton O, Peach H, Moncrieff MDS, et al. The neutrophil-lymphocyte ratio and locoregional melanoma: a multicentre cohort study. Cancer Immunol Immunother. (2020) 69:559-68. doi: 10.1007/s00262-019-02478-7

10. Lee S, Oh SY, Kim SH, Lee JH, Kim MC, Kim KH, et al. Prognostic significance of neutrophil lymphocyte ratio and platelet lymphocyte ratio in advanced gastric cancer patients treated with FOLFOX chemotherapy. BMC Cancer. (2013) 13:350. doi: 10.1186/1471-2407-13-350

11. Miyake M, Morizawa Y, Hori S, Marugami N, Iida K, Ohnishi K, et al. Integrative assessment of pretreatment inflammation-, nutrition, and muscle-based prognostic markers in patients with muscle-invasive bladder cancer undergoing radical cystectomy. Oncology. (2017) 93:259-69. doi: $10.1159 / 000477405$

12. Messager M, Neofytou K, Chaudry MA, Allum WH. Prognostic impact of preoperative platelets to lymphocytes ratio (PLR) on survival for oesophageal and junctional carcinoma treated with neoadjuvant chemotherapy: a retrospective monocentric study on 153 patients. Eur J Surg Oncol. (2015) 41:1316-23. doi: 10.1016/j.ejso.2015.06.007

13. Asano Y, Kashiwagi S, Onoda N, Noda S, Kawajiri H, Takashima T, et al. Platelet-lymphocyte ratio as a useful predictor of the therapeutic effect of neoadjuvant chemotherapy in breast cancer. PLoS ONE. (2016) 11:e0153459. doi: 10.1371/journal.pone.0153459

14. Liu H, Wu Y, Wang Z, Yao Y, Chen F, Zhang H, et al. Pretreatment platelet-to-lymphocyte ratio (PLR) as a predictor of response to first-line platinum-based chemotherapy and prognosis for patients with non-small cell lung cancer. J Thorac Dis. (2013) 5:783-9. doi: 10.3978/j.issn.2072-1439. 2013.12.34

\section{DATA AVAILABILITY STATEMENT}

All datasets generated for this study are included in the article/supplementary material.

\section{AUTHOR CONTRIBUTIONS}

FZ and WG performed the retrieval of data and took part in the statistical analysis for meta-analysis. WG drafted and revised the manuscript. All authors read and approved the final manuscript.

15. Khoja L, Atenafu EG, Templeton A, Qye Y, Chappell MA, Saibil S, et al. The full blood count as a biomarker of outcome and toxicity in ipilimumabtreated cutaneous metastatic melanoma. Cancer Med. (2016) 5:2792-9. doi: $10.1002 / \mathrm{cam} 4.878$

16. Yu JY, Wu XW, Yu H, Li SM, Mao LL, Chi ZH, et al. Systemic immuneinflammation index and circulating T-cell immune index predict outcomes in high-risk acral melanoma patients treated with high-dose interferon. Transl Oncol. (2017) 10:719-25. doi: 10.1016/j.tranon.2017.06.004

17. Cao YJ, Zhang WH, Du WJ, Wang XM, Cao S. Higher preoperative plateletto-lymphocyte ratio is a poor prognostic marker for the early stage malignant melanoma patients. Chin J Cancer Biother. (2018) 25:509-14.

18. Minowa T, Kato J, Hida T, Horimoto K, Sato S, Sawada M, et al. Prognostic role of platelet to lymphocyte and lymphocyte to monocyte ratios in advanced melanoma treated with anti-programmed death-1. Eur J Dermatol. (2018) 28:705-7. doi: 10.1111/1346-8138.14297

19. Qi YL, Zhang Y, Fu XM, Wang AX, Yang YH, Shang YM, et al. Plateletto-lymphocyte ratio in peripheral blood: a novel independent prognostic factor in patients with melanoma. Int Immunopharmacol. (2018) 56:143-7. doi: 10.1016/j.intimp.2018.01.019

20. Wade RG, Robinson AV, Lo MCI, Keeble C, Marples M, Dewar DJ, et al. Baseline neutrophil-lymphocyte and platelet-lymphocyte ratios as biomarkers of survival in cutaneous melanoma: a multicenter cohort study. Ann Surg Oncol. (2018) 25:3341-9. doi: 10.1245/s10434-018-6660-x

21. Wang Y, Ba HJ, Wen XZ, Zhang XS. Relationship between preoperative platelet level and prognosis in patients with resectable acral melanoma. J Chin Oncol. (2019) 25:646-9.

22. Wang YX, Zhang H, Yang YH, Zhang T, Ma XL. Prognostic value of peripheral inflammatory markers in preoperative mucosal melanoma: a multicenter retrospective study. Front Oncol. (2019) 9:995. doi: 10.3389/fonc.2019.00995

23. Yang LG, Xu Y, Luo P, Chen SQ, Zhu HY, Wang CM. Baseline platelet counts and derived inflammatory biomarkers: prognostic relevance in metastatic melanoma patients receiving Endostar plus dacarbazine and cisplatin. Cancer Management Res. (2019) 11:3681-90. doi: 10.2147/CMAR.S194176

24. Moher D, Liberati A, Tetzlaff J, Altman DG, Grp P. Preferred reporting items for systematic reviews and meta-analyses: the PRISMA Statement. PLoS Med. (2009) 6:e1000097. doi: 10.1371/journal.pmed.1000097

25. Stang A. Critical evaluation of the Newcastle-Ottawa scale for the assessment of the quality of nonrandomized studies in meta-analyses. Eur J Epidemiol. (2010) 25:603-5. doi: 10.1007/s10654-010-9491-z

26. Tierney JF, Stewart LA, Ghersi D, Burdett S, Sydes MR. Practical methods for incorporating summary time-to-event data into meta-analysis. Trials. (2007) 8:16. doi: 10.1186/1745-6215-8-16

27. Begg CB, Mazumdar M. Operating characteristics of a rank correlation test for publication bias. Biometrics. (1994) 50:1088-101. doi: 10.2307/2533446

28. Egger M, Smith GD, Schneider M, Minder C. Bias in meta-analysis detected by a simple, graphical test. BMJ. (1997) 315:629-34. doi: 10.1136/bmj.315.7109.629

29. Grivennikov SI, Greten FR, Karin M. Immunity, Inflammation, and Cancer. Cell. (2010) 140:883-99. doi: 10.1016/j.cell.2010.01.025

30. Zhan H, Ma JY, Jian QC. Prognostic significance of pretreatment neutrophilto-lymphocyte ratio in melanoma patients: a meta-analysis. Clin Chim Acta. (2018) 484:136-40. doi: 10.1016/j.cca.2018.05.055 
31. Fu Q, Chen N, Ge C, Li R, Li Z, Zeng B, et al. Prognostic value of tumorinfiltrating lymphocytes in melanoma: a systematic review and meta-analysis. Oncoimmunology. (2019) 8:1593806. doi: 10.1080/2162402X.2019.1593806

32. Bald T, Quast T, Landsberg J, Rogava M, Glodde N, Lopez-Ramos $\mathrm{D}$, et al. Ultraviolet-radiation-induced inflammation promotes angiotropism and metastasis in melanoma. Nature. (2014) 507:109-13. doi: $10.1038 /$ nature 13111

33. Cho MS, Bottsford-Miller J, Vasquez HG, Stone R, Zand B, Kroll MH, et al. Platelets increase the proliferation of ovarian cancer cells. Blood. (2012) 120:4869-72. doi: 10.1182/blood-2012-06-438598

34. Khalid A, Wolfram J, Ferrari I, Mu CF, Mai JH, Yang ZZ, et al. Recent advances in discovering the role of CCL5 in metastatic breast cancer. Mini Rev Med Chem. (2015) 15:1063-72. doi: 10.2174/138955751513150923094709

35. Velez J, Enciso LJ, Suarez M, Fiegl M, Grismaldo A, Lopez C, et al. Platelets promote mitochondrial uncoupling and resistance to apoptosis in leukemia cells: a novel paradigm for the bone marrow microenvironment. Cancer Microenviron. (2014) 7:79-90. doi: 10.1007/s12307-014-0149-3

36. Palumbo JS, Talmage KE, Massari JV, La Jeunesse CM, Flick MJ, Kombrinck KW, et al. Platelets and fibrin(ogen) increase metastatic potential by impeding natural killer cell-mediated elimination of tumor cells. Blood. (2005) 105:17885. doi: 10.1182/blood-2004-06-2272

37. Dunn GP, Old LJ, Schreiber RD. The immunobiology of cancer immunosurveillance and immunoediting. Immunity. (2004) 21:137-48. doi: 10.1016/j.immuni.2004.07.017

38. Man YG, Stojadinovic A, Mason J, Avital I, Bilchik A, Bruecher B, et al. Tumor-infiltrating immune cells promoting tumor invasion and metastasis: existing theories. J Cancer. (2013) 4:84-95. doi: 10.7150/jca.5482

39. Sznurkowski JJ, Zawrocki A, Emerich J, Biernat W. Prognostic significance of $\mathrm{CD} 4(+)$ and $\mathrm{CD} 8(+) \mathrm{T}$ cell infiltration within cancer cell nests in vulvar squamous cell carcinoma. Int J Gynecol Cancer. (2011) 21:717-21. doi: 10.1097/IGC.0b013e3182131f36

40. Mehrazin R, Uzzo RG, Kutikov A, Ruth K, Tomaszewski JJ, Dulaimi $\mathrm{E}$, et al. Lymphopenia is an independent predictor of inferior outcome in papillary renal cell carcinoma. Urol Oncol. (2015) 33. doi: 10.1016/j.urolonc.2014.06.004

41. Nguyen N, Bellile E, Thomas D, McHugh J, Rozek L, Virani S, et al. Tumor infiltrating lymphocytes and survival in patients with head and neck squamous cell carcinoma. Head Neck. (2016) 38:1074-84. doi: 10.1002/hed.24406

42. Templeton AJ, Ace O, McNamara MG, Al-Mubarak M, Vera-Badillo FE, Hermanns T, et al. Prognostic role of platelet to lymphocyte ratio in solid tumors: a systematic review and meta-analysis. Cancer Epidemiol Biomarkers Prev. (2014) 23:1204-12. doi: 10.1158/1055-9965.EPI-14-0146

43. Zhou X, Du YP, Huang ZB, Xu J, Qiu TZ, Wang J, et al. Prognostic value of PLR in various cancers: a meta-analysis. PLoS ONE. (2014) 9:e101119. doi: 10.1371/journal.pone.0101119

44. Cao W, Yao X, Cen D, Zhi Y, Zhu N, Xu L. The prognostic role of platelet-to-lymphocyte ratio on overall survival in gastric cancer: a systematic review and meta-analysis. BMC Gastroenterol. (2020) 20:16. doi: 10.1186/s12876-020-1167-x

45. Jiang S, Liu J, Chen X, Zheng X, Ruan J, Ye A, et al. Platelet-lymphocyte ratio as a potential prognostic factor in gynecologic cancers: a metaanalysis. Arch Gynecol Obstet. (2019) 300:829-39. doi: 10.1007/s00404-01905257-y

46. Cen RX, Li YG. Platelet-to-lymphocyte ratio as a potential prognostic factor in nasopharyngeal carcinoma: a meta-analysis. Medicine. (2019) 98:e17176. doi: 10.1097/MD.0000000000017176

47. Wang X, Ni X, Tang G. Prognostic role of platelet-to-lymphocyte ratio in patients with bladder cancer: a meta-analysis. Front Oncol. (2019) 9:757. doi: $10.3389 /$ fonc. 2019.00757

48. Chen Y, Zhang Z, Fang Q, Jian H. Prognostic impact of platelet-to-lymphocyte ratio on diffuse large B-cell lymphoma: a meta-analysis. Cancer Cell Int. (2019) 19:245. doi: 10.1186/s12935-019-0962-3

Conflict of Interest: The authors declare that the research was conducted in the absence of any commercial or financial relationships that could be construed as a potential conflict of interest.

Copyright (c) 2020 Zhang and Gong. This is an open-access article distributed under the terms of the Creative Commons Attribution License (CC BY). The use, distribution or reproduction in other forums is permitted, provided the original author(s) and the copyright owner(s) are credited and that the original publication in this journal is cited, in accordance with accepted academic practice. No use, distribution or reproduction is permitted which does not comply with these terms. 